\title{
Surface-Controlled Crystal Alignment of Naphthyl End-Capped Oligothiophene on Graphene: Thin-Film Growth Studied by in Situ X-ray Diffraction
}

Huss-Hansen, Mathias K.; Hodas, Martin; Mrkyvkova, Nada; Hagara, Jakub; Jensen, Bjarke B.E.; Osadnik, Andreas; Lützen, Arne; Majková, Eva; Siffalovic, Peter; Schreiber, Frank

Total number of authors:

13

Published in:

Langmuir

Link to article, DOI:

10.1021/acs.langmuir.9b03467

Publication date:

2020

Document Version

Peer reviewed version

Link back to DTU Orbit

Citation $(A P A)$ :

Huss-Hansen, M. K., Hodas, M., Mrkyvkova, N., Hagara, J., Jensen, B. B. E., Osadnik, A., Lützen, A., Majková, E., Siffalovic, P., Schreiber, F., Tavares, L., Kjelstrup-Hansen, J., \& Knaapila, M. (2020). Surface-Controlled Crystal Alignment of Naphthyl End-Capped Oligothiophene on Graphene: Thin-Film Growth Studied by in Situ Xray Diffraction. Langmuir, 36(8), 1898-1906. https://doi.org/10.1021/acs.langmuir.9b03467

\section{General rights}

Copyright and moral rights for the publications made accessible in the public portal are retained by the authors and/or other copyright owners and it is a condition of accessing publications that users recognise and abide by the legal requirements associated with these rights.

- Users may download and print one copy of any publication from the public portal for the purpose of private study or research.

- You may not further distribute the material or use it for any profit-making activity or commercial gain

- You may freely distribute the URL identifying the publication in the public portal 
Subscriber access provided by University Library of Southern Denmark

\section{Interfaces: Adsorption, Reactions, Films, Forces, Measurement Techniques, Charge}

Transfer, Electrochemistry, Electrocatalysis, Energy Production and Storage

\section{Surface-Controlled Crystal Alignment of Naphthyl End-Capped Oligothiophene on Graphene: Thin-Film Growth Studied by In Situ X-ray Diffraction}

Mathias Kasper Huss-Hansen, Martin Hodas, Nada Mrkyvkova, Jakub Hagara, Bjarke Bror Egede Jensen, Andreas Osadnik, Arne Luetzen, Eva Majkova, Peter Siffalovic, Frank Schreiber, Luciana Tavares, Jakob Kjelstrup-Hansen, and Matti Knaapila

Langmuir, Just Accepted Manuscript • DOI: 10.1021/acs.langmuir.9b03467 • Publication Date (Web): 06 Feb 2020

Downloaded from pubs.acs.org on February 9, 2020

\section{Just Accepted}

"Just Accepted" manuscripts have been peer-reviewed and accepted for publication. They are posted online prior to technical editing, formatting for publication and author proofing. The American Chemical Society provides "Just Accepted" as a service to the research community to expedite the dissemination of scientific material as soon as possible after acceptance. "Just Accepted" manuscripts appear in full in PDF format accompanied by an HTML abstract. "Just Accepted" manuscripts have been fully peer reviewed, but should not be considered the official version of record. They are citable by the Digital Object Identifier (DOI@). "Just Accepted" is an optional service offered to authors. Therefore, the "Just Accepted" Web site may not include all articles that will be published in the journal. After a manuscript is technically edited and formatted, it will be removed from the "Just Accepted" Web site and published as an ASAP article. Note that technical editing may introduce minor changes to the manuscript text and/or graphics which could affect content, and all legal disclaimers and ethical guidelines that apply to the journal pertain. ACS cannot be held responsible for errors or consequences arising from the use of information contained in these "Just Accepted" manuscripts. 


\title{
Surface-Controlled Crystal Alignment of Naphthyl
}

\section{End-Capped Oligothiophene on Graphene: Thin-}

\section{Film Growth Studied by In Situ X-ray Diffraction}

Mathias K. Huss-Hansen *,, Martin Hodas'2, Nada Mrkyvkova3,4, Jakub Hagara ${ }^{3,4}$, Bjarke B. E. Jensen $^{5}$, Andreas Osadnik ${ }^{6}$, Arne Lützen ${ }^{6}$, Eva Majkováa ${ }^{3,4}$, Peter Siffalovic ${ }^{3,4}$, Frank Schreiber ${ }^{2}$, Luciana Tavares ${ }^{7}$, Jakob Kjelstrup-Hansen ${ }^{7}$, and Matti Knaapila ${ }^{1}$

${ }^{1}$ Department of Physics, Technical University of Denmark, Kgs. Lyngby, 2800, Denmark

\author{
${ }^{2}$ Institut für Angewandte Physik, Universität Tübingen, Tübingen, 72076, Germany \\ ${ }^{3}$ Institute of Physics, Slovak Academy of Sciences, Bratislava, 84511, Slovakia
}

${ }^{4}$ Centre of Excellence for Advanced Materials Application, Bratislava, 84511, Slovakia

${ }^{5}$ Newtec Engineering A/S, Odense M, 5230, Denmark

${ }^{6}$ Kekulé-Institute for Organic Chemistry and Biochemistry, University of Bonn, Bonn, 53121, Germany
${ }^{7}$ NanoSYD, Mads Clausen Institute, University of Southern Denmark, Sønderborg, 6400, Denmark




\begin{abstract}
KEYWORDS: small $\pi$-conjugated molecules, conjugated oligomers, two-dimensional materials, molecular orientation, surface-controlled alignment, GIXRD
\end{abstract}

\begin{abstract}
We report on the microstructure, morphology, and growth of 5,5'-bis(naphth-2yl)-2,2'-bithiophene (NaT2) thin films deposited on graphene, characterized by grazingincidence X-ray diffraction (GIXRD) and complemented by atomic force microscopy (AFM) measurements. NaT2 is deposited on two types of graphene surfaces: custom-made samples where CVD-grown graphene layers are transferred onto a $\mathrm{Si} / \mathrm{SiO}_{2}$ substrate by us and common commercially transferred $\mathrm{CVD}$ graphene on $\mathrm{Si} / \mathrm{SiO}_{2}$. Pristine $\mathrm{Si} / \mathrm{SiO}_{2}$ substrates are used as a reference. The NaT2 crystal structure and orientation depend strongly on the underlying surface, with the molecules predominantly lying-down on the graphene surface (face-on orientation) and standing nearly out-of-plane (edge-on orientation) on the $\mathrm{Si} / \mathrm{SiO}_{2}$ reference surface. Post growth GIXRD and AFM measurements reveal that the crystalline structure and grain morphology differ depending on whether there is polymer residue left on the graphene surface. In situ GIXRD measurements show that the thickness dependence of the intensity of the (111) reflection from the crystalline edge-on phase does not intersect zero at the beginning of the deposition process, suggesting that an initial wetting layer, corresponding to 1-2 molecular layers, is formed at the surface-film interface. By contrast, the (111) reflection intensity from the crystalline face-on phase grows at a constant rate as a function of film thickness during the entire deposition.
\end{abstract}




\section{Introduction}

Organic semiconductors attract great interest for use in organic electronics, including organic field-effect transistors (OFETs), ${ }^{1,2}$ organic photovoltaics (OPVs), ${ }^{3,4}$ and various chemo- and biosensor, ${ }^{5-8}$ and mechanical sensors. ${ }^{9}$ Much of this application potential as well as fundamental interest stems from the facile tuning of their electronic and spectral properties. These optoelectronic properties are directly related to the structure and morphology in a thin film environment, including intermolecular packing, molecular orientation and molecular-surface interactions. ${ }^{10-13}$ Among organic semiconductors, oligothiophenes form one of the most important and extensively studied material families. ${ }^{11,14-18}$ As a prime example, Geng et al. introduced a family of symmetric naphthyl end-capped oligothiophenes with high crystallinity and stability. ${ }^{19}$ The end-capping of the thiophene rings with aryl groups hinders polymerization and promotes intermolecular packing. We have recently started to focus on the most symmetric variant of these materials, 5,5'-bis(naphth-2-yl)- 2,2'-bithiophene (NaT2, Scheme 1), and investigated the relation between structure and OFET environment, and confirmed the stability hypotheses of Geng and co-workers by X-ray investigations of NAT2 OFETs in operando. ${ }^{20}$ At the same time, Balzer et al. ${ }^{21}$ have found how NaT2 forms an extraordinary fiber-like surface morphology on muscovite mica, presumably originating from the anisotropy of the muscovite surface. These findings make NaT2 an intriguing new candidate when turning to the fundamentals of surface controlled crystal growth.

Graphene and other 2D materials have attracted immense attention owing to their unique mechanical and electronic properties..$^{22-24}$ The use of graphene as a transparent electrode material in combination with organic semiconductors has significant potential in OFETs, OPVs and elsewhere. ${ }^{25-27}$ As most organic semiconductors are $\pi$-conjugated molecules by nature, they are 
able to interact with the surface of the graphene through $\pi-\pi$ and $\mathrm{CH}-\pi$ interactions. Numerous studies using graphene or other 2D materials as templates for molecular growth of small organic molecules have been reported. ${ }^{14,15,27-34}$ A common trend found in these studies is that the organic molecules, which can commonly be thought of as small rigid rods, tend to adopt a face-on (or 'lying-down') orientation on the graphene, with the molecular backbone oriented parallel to the surface. Being able to manipulate the orientation of the highly anisotropic semiconductor molecules allows for better control of the vertical charge transport and light absorption when designing new devices, especially for OPVs.

A number of studies have shown that the quality of the graphene film, which is typically grown by chemical vapor deposition (CVD) on a metallic foil and subsequently transferred onto the device substrate, ${ }^{16}$ has a large influence on the growth behavior of the deposited molecules. ${ }^{27,29,35,36}$ In particular, the presence of residual materials from the transfer process, e.g. PMMA, can lead to growth of molecular phases with different, and often undesirable, orientation. This means a careful study cannot rely on one type of graphene surface but several alternatives should be investigated.

Real-time investigations of small molecule growth, where the measured data is collected in situ during the thin film deposition, is an increasingly popular strategy when studying growth behavior. These include real-time studies using atomic force microscopy (AFM)/low energy electron microscopy (LEEM) ${ }^{37}$ and optical spectroscopy. ${ }^{38}$ In situ grazing incidence X-ray diffraction (GIXRD) combines real-time measurements during the thin film deposition with a commonly employed structural characterization technique for organic molecules. ${ }^{39-42}$ Several studies on conjugated oligomers using in situ GIXRD have been reported. ${ }^{43-50}$ The real-time nature of these experiments allows for detection of transient structural phases and orientational 
transitions during the film formation, which would otherwise be impossible to detect by studying the film post growth.

In this paper, we investigate the structural evolution and crystal orientation of NaT2 deposited on monolayer graphene films employing in situ real-time GIXRD measurements complemented by steady state GIXRD and AFM measurements. Two representative graphene-covered substrate types are used for the depositions; custom-made samples where CVD-grown graphene layers are transferred onto a $\mathrm{Si} / \mathrm{SiO}_{2}$ substrate by us and common commercially transferred CVD graphene on $\mathrm{Si} / \mathrm{SiO}_{2}$. Pristine $\mathrm{SiO}_{2}$ substrates are used as a reference. We find that the orientation of the NaT2 molecules is highly sensitive to the nature of the substrate (graphene vs $\mathrm{SiO}_{2}$ ) and to the quality of the graphene surface (polymer residue vs no polymer residue), and that the emerging crystalline phases exhibit different growth behavior during the early stages of deposition. These findings provide new insight into fundamental growth processes, which are at the same time crucial to control the supramolecular orientation of naphthyl end-capped oligothiophenes on 2D template materials for application.

\section{Experimental Section}

Materials. Scheme 1 shows the chemical structure of the NaT2 molecules used in this study. They were synthesized following the Suzuki cross-coupling protocols reported in the literature. ${ }^{21}$

Scheme 1. Chemical structure of NaT2.

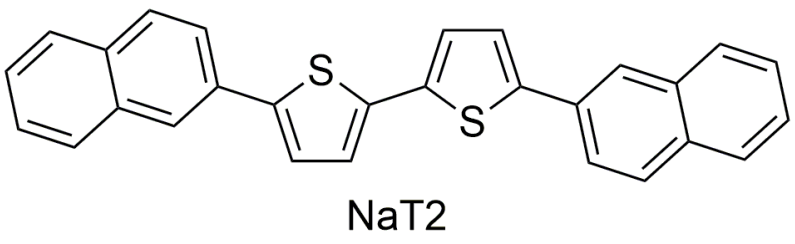

Substrate Fabrication. Two types of graphene surfaces were employed in this study prepared in a similar manner. 
Type I: $\mathrm{SiO}_{2} / \mathrm{Si}$ substrates with $\mathrm{CVD}$ graphene were prepared according to standard procedure. ${ }^{51}$ In short, $\mathrm{CVD}$ graphene on $\mathrm{Cu}$, purchased from Graphenea S.A. (Monolayer Graphene on $\mathrm{Cu}$ ), was spin coated with a homemade solution of PMMA dissolved in anisole. After a short baking step, electrochemical delamination proceeded in order to separate the PMMA supported graphene from $\mathrm{Cu}$. The graphene/PMMA was then transferred to a silicon substrate with $90 \mathrm{~nm} \mathrm{SiO}_{2}$, and a final baking step was performed in order to remove water remnants, and to increase the adhesion between graphene and $\mathrm{SiO}_{2}$. Lastly, the PMMA was removed by placing the substrate in hot acetone for a couple of hours.

Type II: Common commercial CVD graphene on $\mathrm{SiO}_{2} / \mathrm{Si}$ substrates were purchased from Graphenea S.A. (Monolayer Graphene on $\mathrm{SiO}_{2} / \mathrm{Si} 90 \mathrm{~nm}$ ) and used as is. According to the manufacturer ${ }^{52}$, the $\mathrm{CVD}$ graphene is transferred from $\mathrm{Cu}$ to $\mathrm{SiO}_{2} / \mathrm{Si}$ by a wet transfer process. The graphene is protected with a sacrificial PMMA layer and a ferric chloride solution is used for $\mathrm{Cu}$ etching. After the etching process, the graphene is washed and transferred onto the $\mathrm{SiO}_{2} / \mathrm{Si}$ substrate. The PMMA layer is then thermally treated at $150^{\circ} \mathrm{C}$ for 10 hours in inert atmosphere and subsequently removed by submerging in acetone for $30 \mathrm{~min}$ and isopropyl alcohol for $30 \mathrm{~min}$.

Substrate Characterization. The surface energies of the substrates were estimated from contact angle measurements of three test liquids: water, diiodomethane and ethylene glycol (thioglycol in the case of pristine $\mathrm{SiO}_{2}$ ). Contact angles were measured using an automated liquid dispenser and a digital camera, and averaged from at least three measurements per test liquid. The surface energies were then evaluated by linear regression (shown in Figure $\mathrm{S} 1$ in the supporting information) using the Owens-Wendt-Rabel-Kaelbe (OWRK) model incorporated in Young's equation, yielding 
$\frac{\sigma_{l}(1+\cos \theta)}{2 \sqrt{\sigma_{l}^{d}}}=\sqrt{\sigma_{S}^{p}} \sqrt{\frac{\sigma_{l}^{p}}{\sigma_{l}^{d}}}+\sqrt{\sigma_{S}^{d}}$

where $\theta$ is the contact angle, $\sigma_{l}$ is the surface tension of the test liquid, and $\sigma_{s}^{p}, \sigma_{s}^{d}$, $\sigma_{l}^{p}$ and $\sigma_{l}^{d}$ are the polar and dispersive components of the surface energies of solid and liquid.

The Helium ion microscope images were recorded with a Zeiss Nanofab instrument operated at an imaging voltage of $25 \mathrm{kV}$, a beam current of $0.1 \mathrm{pA}$, and no charge compensation. An Everhart-Thornley detector was used to acquire the secondary electron signal.

NaT2 Thin Film Deposition. The NaT2 thin-film was deposited atop the employed substrates by vacuum sublimation. The base vacuum pressure was below $3 \times 10^{-8} \mathrm{mbar}$. The custom-made deposition chamber is equipped with a $360^{\circ}$ cylindrical X-ray beryllium window, ${ }^{53}$ allowing the incoming and outgoing X-rays to penetrate for simultaneous GIXRD measurements. Prior to deposition, the graphene substrates were annealed at $300^{\circ} \mathrm{C}$. The substrate temperature was kept at $50^{\circ} \mathrm{C}$ during deposition. The typical deposition rate was $0.03 \AA \mathrm{s}^{-1}$ and the deposition was controlled by a mechanical shutter.

UV-Vis Absorption Measurements. The NaT2 was deposited atop two BK7 glass substrates in a similar manner to what is described above with a nominal film thickness of $51 \mathrm{~nm}$. One substrate had a monolayer of graphene transferred according to the same procedure as described above. The absorption spectra were measured using a Shimadzu UV-2700 spectrometer in the UV-VIS spectrum. The spectrometer used an integrating sphere add-on to measure absorption. The absorption curve of graphene was measured separately and has been subtracted from the NaT2 on graphene absorption curve.

Characterization of Final NaT2 Thin Films. The final thin films were characterized by AFM (Dimension 3100, Veeco) operated in tapping mode. The AFM images were subsequently flattened and analyzed using the SPIP software package from Image Metrology. 
The post growth 2D GIXRD measurements were performed using a custom-designed laboratory X-ray scattering setup (Nanostar, Bruker AXS) equipped with a liquid-metal jet anode X-ray source (MetalJet D2+, Excillum). The X-ray energy was $9.25 \mathrm{keV}$ (Ga Ka line), and the angle of incidence was $0.18^{\circ}$. In this configuration, the $\mathrm{X}$-ray footprint spans across the entire sample. The scattering patterns were collected within hours of the deposition using an Imaging Plate Detector with an exposure time of 30 minutes. The GIXRD patterns are invariant to azimuthal rotation of the sample due to the polycrystalline nature of the CVD transferred graphene, i.e. some amount of the NaT2 crystallites will always be in Bragg condition due to the random in-plane orientation of the individual graphene domains.

\section{Real-time Characterization of NaT2 Thin Films during Deposition. In situ GIXRD}

measurements were performed during the deposition process using the same setup as in the post growth experiments, but with a two-dimensional hybrid pixel detector (Pilatus 300, Dectris) used to collect the 2D images. The sample-to-detector distance was calibrated to $219.4 \mathrm{~mm}$ and the exposure time was 3 min per image. A custom-made beamstop was placed directly after the exit window of the deposition chamber to minimize air scattering from the primary beam. The data was processed using a combination of GIXSGUI ${ }^{54}$ and self-programmed MATLAB scripts. In order to obtain a sufficient peak to background ratio for the peak fitting procedure, the GIXRD images were grouped in time. The diffracted intensity profiles were fitted with a Gaussian function after texture- and solid-angle corrections and background subtraction. Consequently, the low-thickness range at the beginning of the deposition process is inaccessible due to the low diffraction intensity of the Bragg reflections and insufficient peak to background ratio. Nevertheless, the relatively high crystallinity of the NaT2 thin film allowed for tracking of all three phases in real time. The intensity of the diffraction spot is proportional to the number of 
crystallites in Bragg condition if we assume that the typical separation of the diffracting crystallites is much larger than the transverse coherence length of the laboratory X-ray source. ${ }^{55}$

\section{Results and Discussion}

\section{Substrates}

Table 1 lists surface energies of the employed substrates. The data shows that the surface energy of the graphene-covered substrates is significantly lowered by the addition of graphene when compared to pristine $\mathrm{SiO}_{2}$. There are no significant differences in the surface energies between the Type I and Type II surfaces, as can be seen by the facts that both are several times less polar than pristine $\mathrm{SiO}_{2}$ but show twice as much possibility to undergo dispersive (van der Waals type) interactions based on the measured dispersive component of the surface energies.

Table 1. Surface Energy of Substrates ${ }^{\mathrm{a}}$

\begin{tabular}{|c|c|c|c|c|c|c|c|}
\hline \multirow[b]{2}{*}{ Substrate } & \multicolumn{4}{|c|}{ Contact angle [deg] } & \multirow[b]{2}{*}{$\begin{array}{l}\sigma_{S}^{p} \quad[\mathrm{~mJ} \\
\mathrm{m}-2]\end{array}$} & \multirow[b]{2}{*}{$\begin{array}{l}\sigma_{s}^{d}[\mathrm{~mJ} \\
\mathrm{m}-2]\end{array}$} & \multirow[b]{2}{*}{$\begin{array}{l}\text { бs [mJ } \\
\mathrm{m}-2]\end{array}$} \\
\hline & Water & Diiodomethane & $\begin{array}{l}\text { Ethylene } \\
\text { Glycol }\end{array}$ & Thioglycol $^{\mathrm{b}}$ & & & \\
\hline $\begin{array}{l}\text { Type I } \\
\text { graphene }\end{array}$ & $\begin{array}{ll}82.3 & \pm \\
0.9 & \end{array}$ & $38.3 \pm 1.0$ & $\begin{array}{ll}50.4 \quad \pm \\
1.1 & \end{array}$ & - & 2.19 & 38.1 & 40.3 \\
\hline $\begin{array}{l}\text { Type II } \\
\text { graphene }\end{array}$ & $\begin{array}{l}83.4 \\
1.5\end{array}$ & $36.5 \pm 1.3$ & $\begin{array}{l}54.1 \quad \pm \\
1.1\end{array}$ & - & 1.60 & 39.0 & 40.6 \\
\hline $\mathrm{SiO} 2$ & $\begin{array}{l}36.3 \quad \pm \\
0.2\end{array}$ & $46.4 \pm 0.1$ & - & $46.4 \pm 0.9$ & 39.9 & 17.3 & 57.2 \\
\hline
\end{tabular}




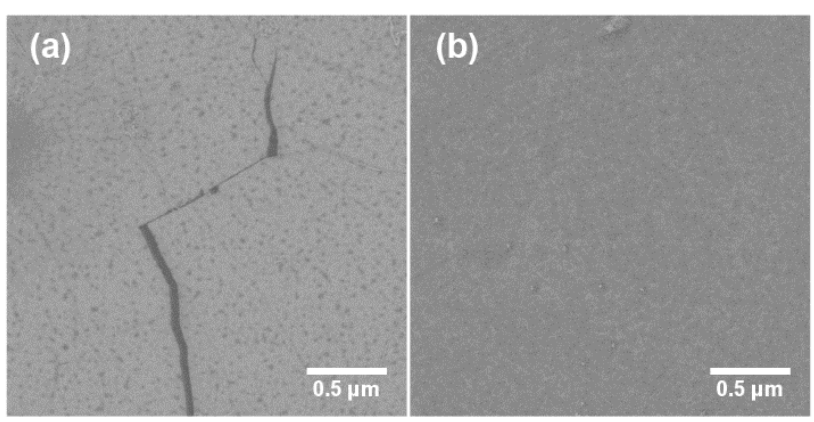

Figure 1. HIM images of the graphene surfaces. (a) Type I graphene. (b) Type II graphene.

To further characterize the substrate surface, helium ion microscopy (HIM) was employed. Figure 1 shows HIM images of the Type I graphene-covered substrate (Figure 1a) and the Type II graphene-covered substrate (Figure 1b). The HIM images indicate that both the Type I and Type II graphene films display a high degree of surface coverage with some cracks, which appear darker on the HIM image. On the Type I graphene, there are several dark spots (Figure 1a) speckled throughout. Identical features can be seen on AFM topographies of the surface (see Supporting Information, Figure S2a,b) and we attribute this to leftover PMMA residue from the graphene transfer process, since the features shown are similar to the ones observed in the litterature. ${ }^{56}$ By comparison, the Type II graphene does not exhibit similar surface imperfections (Figure 1b). The typical surface roughness of the graphene, as measured by AFM, is tabulated in Table S1 (see supplementary). The typical surface roughness of the Type I graphene surface is approximately three times higher than for the Type II graphene surface, suggesting that the residual PMMA is lying on top the otherwise flat graphene. 


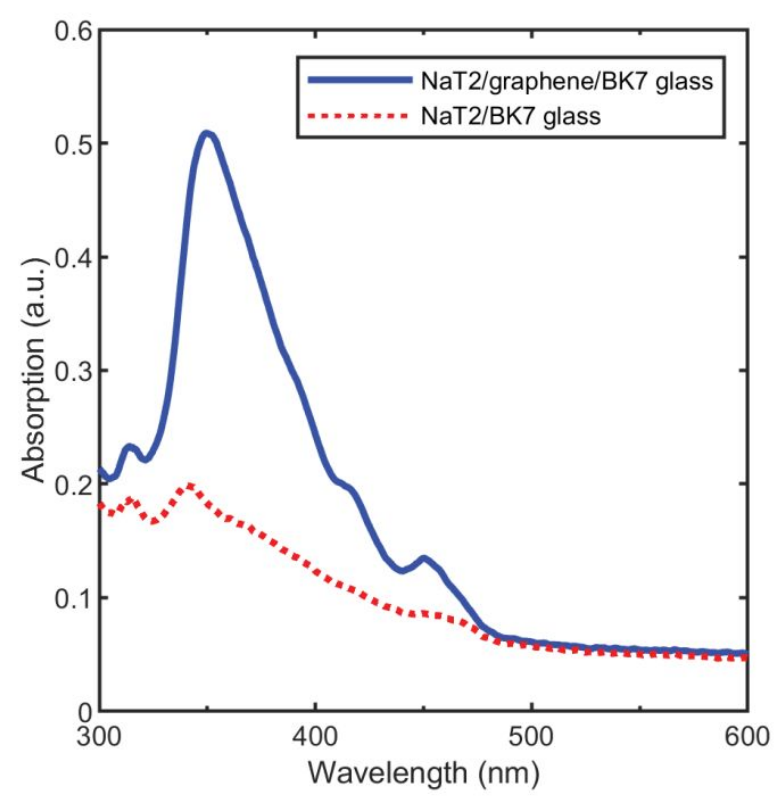

Figure 2. Absorption spectra of NaT2 (nominal thickness $=51 \mathrm{~nm}$ ) on monolayer graphene (transferred to BK7 glass substrate) and BK7 glass substrate. The absorption spectrum from monolayer graphene transferred to BK7 glass was measured separately and subtracted from the NaT2/graphene/BK7 glass spectrum.

\section{Photophysical Properties}

Figure 2 shows the UV-Vis absorption spectra of the as-prepared NaT2 films with and without a monolayer (ML) graphene film. It is immediately apparent that the absorption of the NaT2 film on graphene is much higher than its counterpart, with an approximate increase of $250 \%$ in absorption at the absorption peak. The absorption peak of the NaT2 film without graphene has a maximum at $340 \mathrm{~nm}$, which is consistent with previous literature reports, ${ }^{19}$ and corresponds to the $\pi-\pi^{*}$ transition. By contrast, the NaT2 film on graphene is slightly red-shifted, with an absorption maximum at $350 \mathrm{~nm}$ and two shoulders at $416 \mathrm{~nm}$ and $450 \mathrm{~nm}$. The two shoulders are also present in the absorption spectrum of the NaT2 film without graphene as shown by the normalized absorption curves in Figure S3 (Supporting Information). The increase in absorption 
from the NaT2 film on graphene hints at a preferential orientation of the molecules along the graphene substrate, since the absorption transition dipole of NaT2 lies in the direction parallel to the long molecular axis along the backbone, which is often the case for conjugated oligomers. ${ }^{57}$ We propose that the minor spectral changes occur because the incoming light couple with different strengths to the different transitions depending on whether the molecules are oriented face-on or edge-on, similar to the polarization-dependent absorption observed in other organic crystals..$^{58}$

(a)

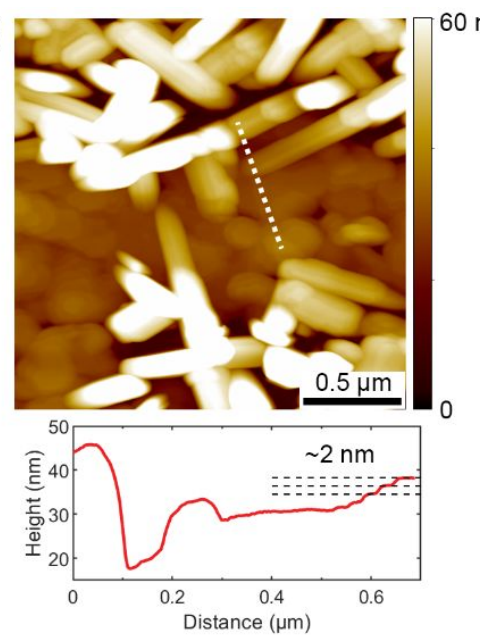

(c)

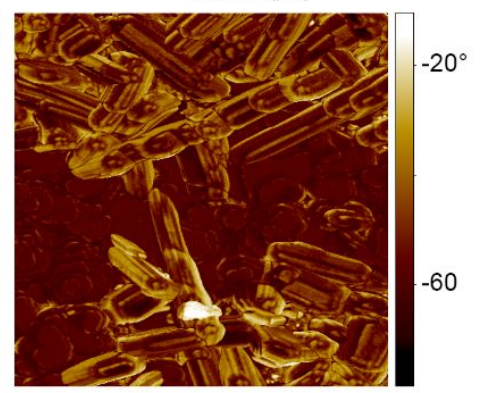

(b)
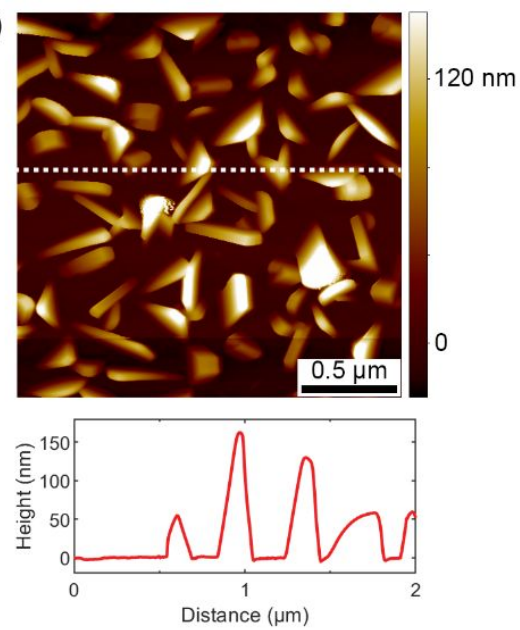

(d)

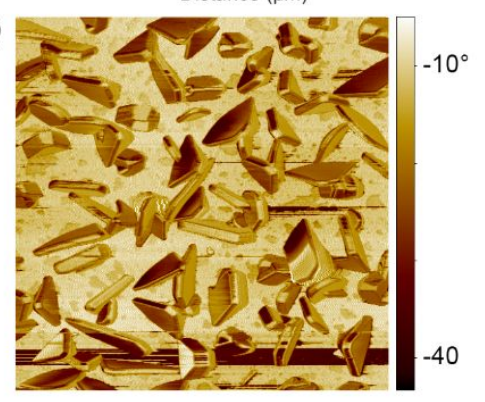

Figure 3. AFM images of the final NaT2 thin films grown on CVD graphene films. (a,b) AFM topographies of the films deposited on Type I and Type II graphene, respectively, with corresponding characteristic cross-sectional height profiles. (c,d). AFM phase images corresponding to the topographies above. 


\section{Post-Growth Thin Film}

Figure 3a,b show AFM topographies and corresponding characteristic cross-sectional height profiles of the final NaT2 thin films after deposition on the two types of graphene. NaT2 grown on Type I graphene exhibits two distinct grain morphologies, as evidenced by the topographic map in Figure 3a: island-like flat formations with distinct terraces (middle right and bottom left of Figure 3a) and needle-like structures (top and bottom of Figure 3a). Flat-island formations are also observed for NaT2 grown on $\mathrm{SiO}_{2}$ (Figure S4) and self-assembled monolayers (SAMs) of octadecyltrichlorosilane (OTS), ${ }^{59}$ and generally correspond to standing molecules with near upright orientation (i.e. edge-on) for small rod-like molecules. The cross-sectional height profile furthermore reveals that the terrace step height corresponds almost exactly to the length of one molecule $(\sim 2 \mathrm{~nm})$. The needle-like structures, also referred to as nanofibers, have widths in the hundred-nanometer range and are several tens of nanometers high. The fibers appear to locally grow in well-defined directions with six-fold symmetry, as illustrated by the Fourier transformation of the phase-image (Figure S5 in the Supporting Information), which might correspond to the six-fold symmetry of the underlying graphene domain. Such nanofiber structures have previously been observed for NaT2 grown on muscovite mica sheets, ${ }^{21}$ and for other conjugated oligomers, including pentacene grown on thermally treated graphene, ${ }^{27,47}$ and are also known for conjugated polymers like polyflourenes. ${ }^{60}$ The corresponding AFM phase image (Figure 3c) likewise shows a difference in phase contrast between the nanofibers and the flat-island formations. A phase contrast also exists between the center and edge of the terraced islands, highlighting the individual steps.

In contrast, NaT2 film grown on Type II graphene (Figure 3b) exhibits a morphology of faceted crystalline grains with extremely well defined growth direction and sharp edges. The 
visually apparent grains range from 50 to 150 nanometers in height and display relatively incomplete surface coverage. The corresponding AFM phase-image (Figure 3d) shows a phase contrast between the different edges of the faceted crystals, as well as a phase contrast between the crystal phases and the underlying substrate. The phase contrast together with the sharp edges of the topography map suggests that NaT2 forms large 'single crystal-like' crystal grains atop the Type II graphene with well-defined crystal facets.

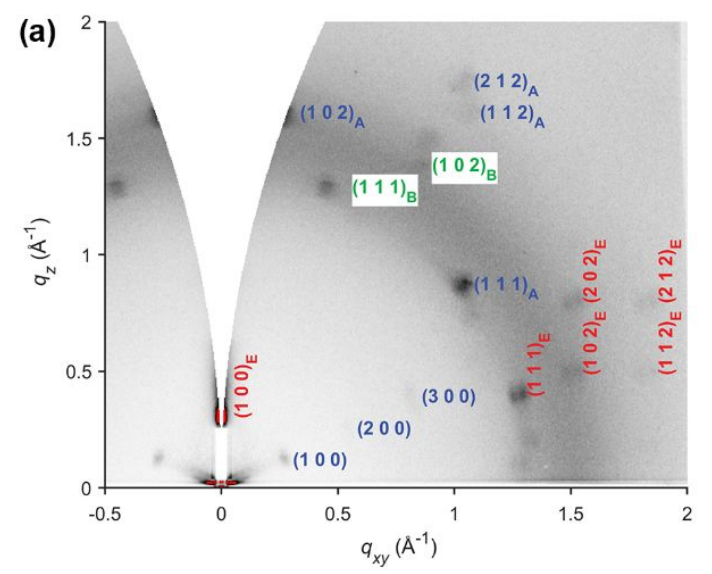

(b)

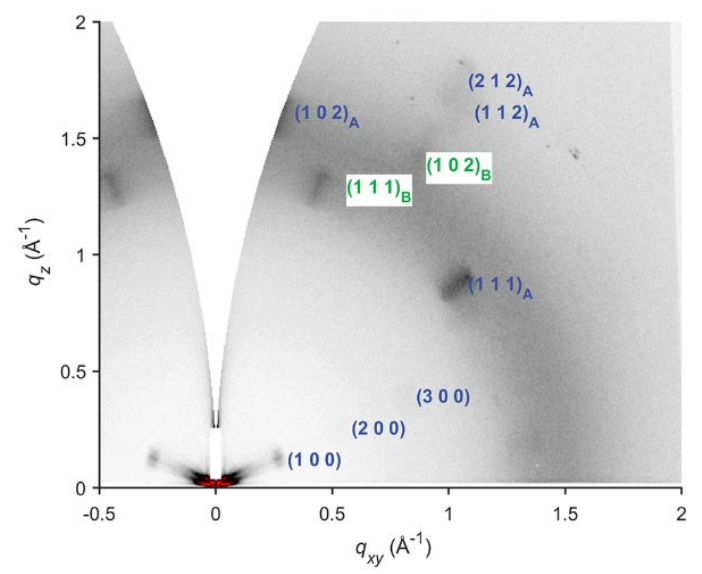

(c)
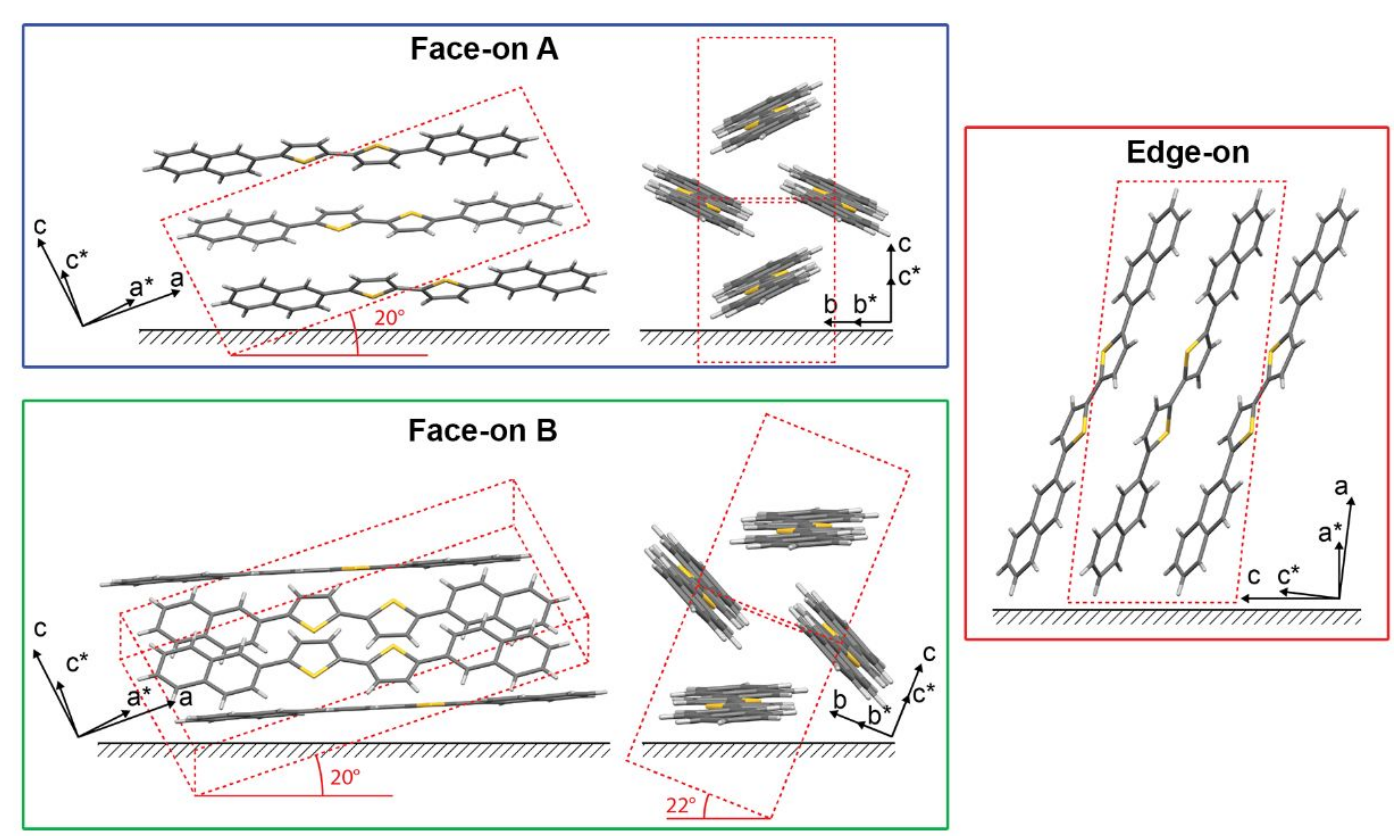
Figure 4. $(a, b)$ GIXRD patterns of NaT2 thin films deposited on Type I and Type II graphene substrates, respectively. (c) Proposed arrangements of NaT2 molecules with face-on and edge-on orientations. For all schematics, the view is taken to be parallel to the substrate plane. The right view in the two face-on schematics is rotated by 90 degrees to illustrate the difference in the tilt of the $b$-axis (corresponding to a view along the molecular backbone). The direct- and reciprocal lattice vectors are shown in the bottom corner and the unit cell is marked by the dotted lines. The border colors correspond to the color of the reflection indices in (a) and (b).

Figure 4 shows two-dimensional GIXRD patterns of the final NaT2 films. NaT2 film grown on Type I graphene (Figure 4a) displays intense (100) reflections (originating from the molecular long axis) along the out-of-plane $q_{z}$ direction, indicating that a large proportion of the molecules adopt an edge-on orientation with the (h00) plane vectors directed parallel to the surface normal. The true (h00) reflections are in principle forbidden in grazing incidence geometry, but are nevertheless observed due to the orientation distribution of crystallites around the true $(h 00)$ axis. In addition, several reflections from the edge-on phase are present at higher values of $q_{x y}$, indicating that the NaT2 molecules adopt a multilayer structure with a high degree of alignment in-plane as well as out-of-plane. The unit cell choice with mosaic (100)-texture and $\boldsymbol{a}$ as the molecular long axis follows the notation described elsewhere. ${ }^{20}$ The reflections from the observed edge-on phase correspond closely to the molecular packing previously reported for NaT2 thin-film on $\mathrm{SiO}_{2}\left(a=20.31 \AA, b=6.00, c=8.17\right.$ and $\left.\beta=96.64^{\circ}\right) .{ }^{20}$

Moreover, NaT2 film grown on Type I graphene shows (100) reflections that are azimuthally inclined $27^{\circ}$ with respect to $\mathrm{q}_{\mathrm{xy}}$, indicating that some of the molecules adopt face-on orientation, with the molecular long axis directed mostly along the substrate surface (Figure 4c). Two highly visible (111) reflections found equidistant from the primary beam are angled $18^{\circ}$ and $49^{\circ}$ from 
$q_{z}$, respectively, suggesting the existence of two different crystalline phases with face-on orientation. Together with the (102) reflections, azimuthally rotated $45^{\circ}$ and $-13^{\circ}$ from the (111) reflections, the tilt of the $b$-axis with respect to the surface can be determined. The primary faceon phase (i.e. the phase with the brightest (111) reflection spot), denoted 'A' from now on, corresponds to the case where the $b$-axis is lying parallel to the substrate surface. Conversely, the secondary face-on phase ('B') has the b-axis tilted $22^{\circ}$ from the surface. The reflections from both phases are successfully indexed (see Figure S6 in the Supporting Information) with the same lattice parameters as the edge-on phase, indicating that the three phases are identical except for their orientation with respect to the substrate surface.

Figure $4 \mathrm{c}$ summarizes the proposed packing schemes for all three phases. Here we have assumed that the packing of the molecules inside the unit cell is identical to what is reported for single crystalline NaT2. Due to the herringbone packing of the NaT2 molecules, a face-on orientation of the unit cell implies that either both molecules are oriented with a small tilt between the molecular short-edge and the surface (which is the case for the face-on A phase), or that half the molecules adopt a near flat orientation while the other half are significantly inclined towards the surface normal (as indicated by the face-on B phase). The isotropic halo observed at $q=1.5 \AA^{-1}$ can be attributed to scattering from the underlying amorphous $\mathrm{SiO}_{2}$, since the choice of incidence angle is slightly above the critical angle of $\mathrm{SiO}_{2}$ in order to maximize the film peak intensities.

The NaT2 thin film grown on Type II graphene (Figure 4b) does not display clear (h00) crystalline reflections along the $q_{z}$ direction, nor does it display any off-axis peaks attributed to the edge-on phase, indicating that a few or none of the molecules adopt edge-on orientation on 
Type II graphene. Only reflections from the two phases with molecular face-on orientation are clearly present.

The differences in NaT2 thin-film structure on the two types of graphene surfaces is attributed to residual PMMA left over from the graphene transfer process present on the Type I graphene. This is likely because the polymer acts as a template for growth of crystals with molecules adopting edge-on orientation or because the nucleation of the edge-on oriented crystal phase is facilitated by the increased surface roughness on the Type I graphene, or a combination of both. The latter scenario agrees with the prior literature where rough surfaces are known to accelerate heterogeneous nucleation by lowering the nucleation barrier height. ${ }^{61}$ In areas with no PMMA residue on the Type I graphene, the strong interactions between the $\pi$-electrons and the graphene facilitate the growth of NaT2 crystals with the molecules oriented face-on and we observe nanofiber morphology. Likewise, on the Type II graphene with no PMMA residue, the grapheneNaT2 interactions dominate and only crystals phases with face-on orientation of the molecules are observed. These results indicate that the supramolecular orientation of the NaT2 thin-films deposited on graphene can vary significantly depending on the amount of residual PMMA left on the graphene film. 


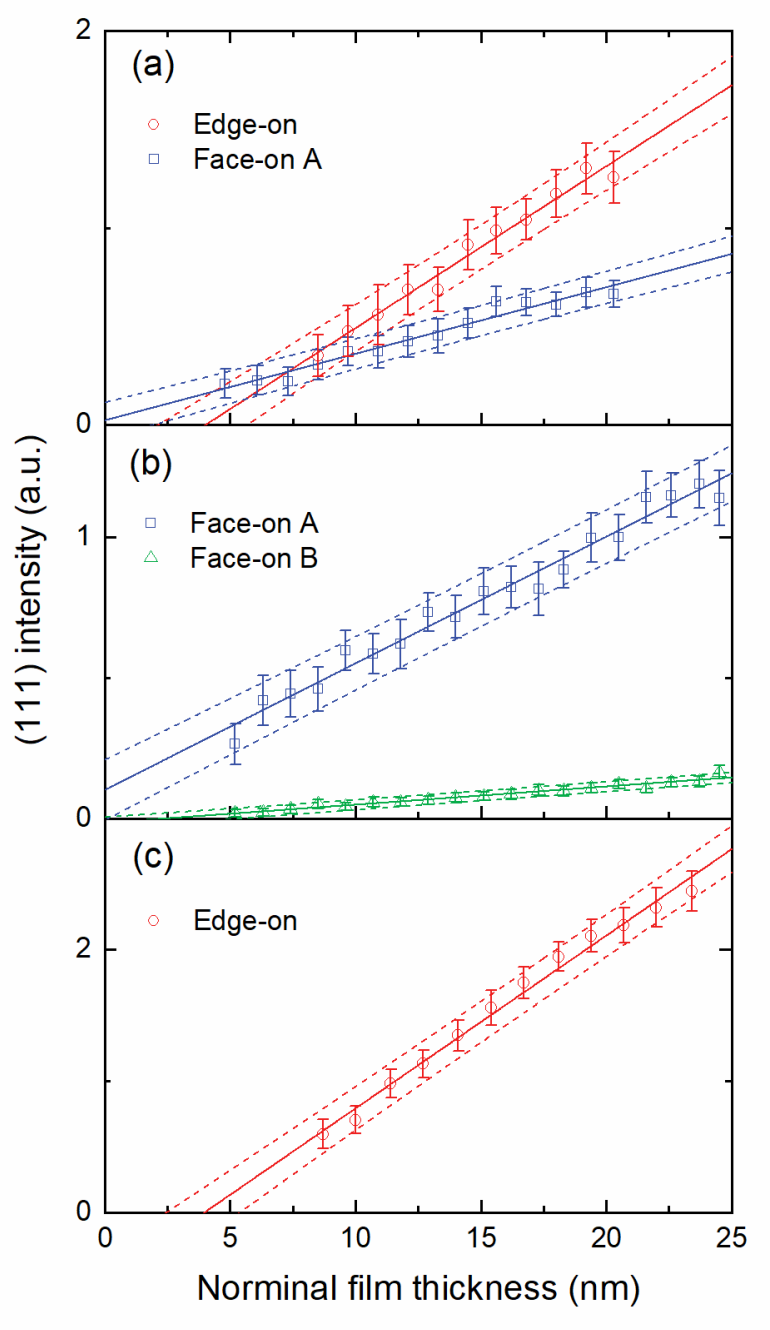

Figure 5. Integrated intensity of the (111) reflection as a function of nominal film thickness. (a) NaT2 deposited on Type I graphene. (b) NaT2 deposited on Type II graphene. (c) NaT2 deposited on $90 \mathrm{~nm} \mathrm{SiO} 2$. The solid lines are linear fits to the data and the dashed lines indicate the corresponding $95 \%$ confidence intervals.

\section{In Situ GIXRD Measurements during Deposition}

During the deposition of the samples, in situ GIXRD measurements were performed in order to monitor the growth of competing crystalline phases. Figure 5 evaluates (111) reflection intensity 
for the three phases identified by post-growth characterization. Figure 5a shows the evolution of the integrated (111) reflection intensity for the deposition of NaT2 on Type I graphene substrate. The growth of the crystalline face-on A phase is evidently linear during the deposition. The fitted slope intersects zero at the start of the deposition, suggesting that the volume of the face-on A phase grows linearly immediately upon opening the deposition shutter. The same tendency is observed for the crystalline face-on A phase grown on Type II graphene (Figure 5b), where the linear fit to the (111) reflection similarly passes through zero at the onset of the deposition (within the given confidence interval). Likewise, the NaT2 face-on B phase displays a linear growth of the (111) reflection on both types of graphene. The integrated (111) reflection intensity of the NaT2 face-on B phase on Type I graphene is shown on Figure S7 in the Supplementary Information. In contrast, although the (111) reflection intensity pertaining to the crystalline edge-on phase shows linear growth on Type I graphene (Figure 5a), the corresponding linear fit does not cross zero at the beginning of the deposition (within the given confidence interval). Instead, the extrapolated (111) reflection intensity starts at approximately four $\mathrm{nm}$ nominal film thickness (corresponding to 2 molecular layers). A similar behavior is found for the $\mathrm{NaT} 2$ edge-on phase on $\mathrm{SiO}_{2}$ (Figure 5c), suggesting that the initial non-linear growth behavior is in part decoupled from the surface interaction and could be inherent to the formation of the edge-on phase. The evolution of the NaT2 edge-on (111) reflection intensity hints at changes from early stage (sub-ML) to later stage (several MLs) growth. The trend is mirrored by the strong (100) reflection, see Figure S8 in the Supplementary Information.

The trends identified in Figure 5 provide us with the following scenarios. Following the growth of the two phases on Type I graphene (Figure 5a), one could be inclined to infer that the edge-on phase grows on top of the face-on phase. In this scenario, the edge-on structure only 
starts to nucleate after a certain number of face-on layers have formed. This behavior has previously been observed for pentacene grown on another two-dimensional material, hexagonal boron nitride $(h-\mathrm{BN}) .{ }^{28}$ However, this scenario does not account for the growth behavior of the edge-on phase on $\mathrm{SiO}_{2}$ (Figure 5c) and it does not agree with the post-growth morphology, where the two phases appear to be forming in separate areas (Figure 3a).

Another scenario is the formation of a transient structure during the early stages of deposition with an accompanying change in lattice parameters. Such transient structures have been observed in other small molecules, ${ }^{11,43}$ and are commonly attributed to substrate induced strain effects. In this scenario, the position of the (111) reflection would change according to the lattice parameters of the transient structure during the deposition. Unfortunately, the signal to noise ratio is not sufficiently high during the early deposition stages and thus does not allow for detection of transient structures within the first few MLs. Previous post-growth studies of thin film NaT2 on $\mathrm{SiO}_{2}$ using synchrotron radiation revealed a singular crystalline phase, ${ }^{20}$ suggesting that if the molecular structure is indeed different within the first ML/few MLs, it is strictly a transient phase. The thin film is likely to undergo reordering after stopping the deposition, ${ }^{43}$ and therefore the lifetime of any transient structure cannot reliably be determined from post-growth measurements.

Assuming that the total volume of crystals is accounted for, the intensity of the (111) reflection after the deposition of several MLs would be identical whether the molecules had directly formed the resolved edge-on phase or had undergone a transformation from a transient phase. Therefore, the formation of a transient phase within the first few MLs alone cannot explain the growth behavior observed for the edge-on phase (Figure 5). 
Instead, we propose that the non-linear growth of the edge-on phase during the early stages of deposition is due to the formation of an initial wetting layer. In this scenario, the wetting layer might be fully or partially disordered or crystalline with a different crystal structure compared to the subsequent layers. In the case that the wetting layer forms partially or fully ordered crystals with a similar crystal structure as the rest of the film, the growth rate of the wetting layer is apparently slower than for the subsequent layers. We speculate that several kinetic factors, such as interlayer transport or slower nucleation rate, might contribute to a slower initial growth rate of the wetting layer. We also note that no wetting layer appears to form during the growth of the face-on phase on graphene since the curve extrapolates through zero intensity. The formation of a wetting layer at the film-surface interface for only certain crystal phases has previously been observed for chemically similar molecules. ${ }^{62}$

\section{Conclusions}

The structure and crystalline orientation of NaT2 depend heavily on the underlying surface and surface quality. We find that the NaT2 crystallites are standing out-of-plane on $\mathrm{SiO}_{2}$ and predominantly lying on the graphene surface, and this is reflected by a 2.5 times higher photoabsorption in the latter case when measured along the surface normal. GIXRD measurements reveal three distinct crystal phases of NaT2 (two face-on phases and one edge-on phase) on the investigated custom-transferred graphene, while NaT2 films deposited on commercially transferred graphene show only the two face-on phases. AFM measurements show that the edge-on phase and the face-on phases grow with two distinct grain morphologies on the custom-transferred graphene (fiber-like and island-like grains, respectively), while on commercially transferred graphene NaT2 grows as faceted crystal grains. We attribute the difference in observed thin-film structure and morphology on the two types of graphene to 
residual PMMA left over from the transfer process, which is only found on the customtransferred graphene. In situ GIXRD measurements show how the intensity of (111) reflection grows linearly with time (at constant deposition rate) for all three phases of NaT2. However, extrapolation of the data to the early stages of deposition (i.e. within the first few molecular layers) shows that the edge-on phase does grow linearly from the onset. Instead, the extrapolated growth intersect zero intensity at a nominal thickness of $\sim 4 \mathrm{~nm}$ (corresponding to 2 molecular layers), suggesting that an initial wetting layer is formed. In comparison, the (111) reflection intensity of both crystals phases with face-on orientation intersect zero at $0 \mathrm{~nm}$ nominal film thickness, indicating an uninterrupted linear growth from the beginning of the deposition.

The surface controlled crystal alignment demonstrated here provides an insight into the complex dynamics of small molecule growth for graphene-based electronic devices. This can be further expanded to studies of other molecules and surfaces, including raising the length of the thiophene rod up to the oligomer-polymer limit as it has been shown elsewhere for oligopolyfluorenes..$^{63,64}$

\section{ASSOCIATED CONTENT}

\section{Supporting Information}

Linear regressions lines against contact angle data (Eq. 1), additional AFM topographies, surface roughness data, normalized absorption spectra, Fourier transformation of the AFM phase-image in Figure 3c and additional thickness dependent GIXRD reflection intensity data.

\section{AUTHOR INFORMATION \\ Corresponding Author \\ *E-mail: mathias.huss-hansen@fysik.dtu.dk}




\section{Notes}

The authors declare no conflict of interest.

\section{ACKNOWLEDGMENTS}

M. K. H.-H. acknowledges the COST Action CA15107 (MultiComp). M. H. acknowledges the financial support of Alexander von Humboldt Foundation. The authors also acknowledge the support of the APVV-17-0352 project, the DAAD/SAV grant and the DFG agency.

\section{References}

(1) Murphy, A. R.; Fréchet, J. M. J. Organic Semiconducting Oligomers for Use in Thin Film Transistors. Chem. Rev. 2007, 107, 1066-1096.

(2) Sirringhaus, H. 25th Anniversary Article: Organic Field-Effect Transistors: The Path Beyond Amorphous Silicon. Adv. Mater. 2014, 26, 1319-1335.

(3) McDowell, C.; Abdelsamie, M.; Toney, M. F.; Bazan, G. C. Solvent Additives: Key Morphology-Directing Agents for Solution-Processed Organic Solar Cells. Adv. Mater. 2018, 30, 1-30.

(4) Coughlin, J. E.; Henson, Z. B.; Welch, G. C.; Bazan, G. C. Design and Synthesis of Molecular Donors for Solution-Processed High-Efficiency Organic Solar Cells. Acc. Chem. Res. 2014, 47, 257-270.

(5) Evans, R. C.; Douglas, P. Design and Color Response of Colorimetric Multilumophore Oxygen Sensors. ACS Appl. Mater. Interfaces 2009, 1, 1023-1030.

(6) Thomas, S. W.; Joly, G. D.; Swager, T. M. Chemical Sensors Based on Amplifying 
Fluorescent Conjugated Polymers. Chem. Rev. 2007, 107, 1339-1386.

(7) Wu, J.; Liu, W.; Ge, J.; Zhang, H.; Wang, P. New Sensing Mechanisms for Design of Fluorescent Chemosensors Emerging in Recent Years. Chem. Soc. Rev. 2011, 40, 34833495.

(8) Wang, B.; Queenan, B. N.; Wang, S.; Nilsson, K. P. R.; Bazan, G. C. Precisely Defined Conjugated Oligoelectrolytes for Biosensing and Therapeutics. Adv. Mater. 2019, 31, 121.

(9) Cingil, H. E.; Boz, E. B.; Wang, J.; Stuart, M. A. C.; Sprakel, J. Probing Nanoscale Coassembly with Dual Mechanochromic Sensors. Adv. Funct. Mater. 2016, 26, 14201427.

(10) Fichou, D. Structural Order in Conjugated Oligothiophenes and Its Implications on OptoElectronic Devices. J. Mater. Chem. 2000, 10, 571-588.

(11) Mannebach, E. M.; Cai, Z.; Himpsel, F. J.; Evans, P. G.; Spalenka, J. W.; Johnson, P. S. High Hole Mobility and Thickness-Dependent Crystal Structure in $\alpha, \omega-$ Dihexylsexithiophene Single-Monolayer Field-Effect Transistors. Adv. Funct. Mater. 2012, 23, 554-564.

(12) Jones, A. O. F.; Chattopadhyay, B.; Geerts, Y. H.; Resel, R. Substrate-Induced and ThinFilm Phases: Polymorphism of Organic Materials on Surfaces. Adv. Funct. Mater. 2016, $26,2233-2255$.

(13) Knaapila, M. Conjugated Polymers And Oligomers: Structural And Soft Matter Aspects; World Scientific: Singapore, 2018. 
(14) Surin, M.; Leclère, P.; De Feyter, S.; Abdel-Mottaleb, M. M. S.; De Schryver, F. C.; Henze, O.; Feast, W. J.; Lazzaroni, R. Molecule - Molecule versus Molecule - Substrate Interactions in the Assembly of Oligothiophenes at Surfaces. J. Phys. Chem. B 2006, 110, $7898-7908$.

(15) Gus'kova, O. A.; Mena-Osteritz, E.; Schillinger, E.; Khalatur, P. G.; Bäuerle, P.; Khokhlov, A. R. Self-Assembled Monolayers of $\beta$-Alkylated Oligothiophenes on Graphite Substrate: Molecular Dynamics Simulation. J. Phys. Chem. C 2007, 111, 7165-7174.

(16) Kim, K. S.; Zhao, Y.; Jang, H.; Lee, S. Y.; Kim, J. M.; Kim, K. S.; Ahn, J.-H.; Kim, P.; Choi, J.-Y.; Hong, B. H. Large-Scale Pattern Growth of Graphene Films for Stretchable Transparent Electrodes. Nature 2009, 457, 706-710.

(17) Wang, J.; De Jeu, W. H.; Ziener, U.; Polinskaya, M. S.; Ponomarenko, S. A.; Ruecker, U.; Ruderer, M. A.; Herzig, E. M.; Müller-Buschbaum, P.; Moeller, M.; et al. Monolayer Properties of Asymmetrically Substituted Sexithiophene. Langmuir 2014, 30, 2752-2760.

(18) De Jeu, W. H.; Rahimi, K.; Ziener, U.; Vill, R.; Herzig, E. M.; Müller-Buschbaum, P.; Möller, M.; Mourran, A. Substituted Septithiophenes with End Groups of Different Size: Packing and Frustration in Bulk and Thin Films. Langmuir 2016, 32, 1533-1541.

(19) Tian, H.; Shi, J.; He, B.; Hu, N.; Dong, S.; Yan, D.; Zhang, J.; Geng, Y.; Wang, F. Naphthyl and Thionaphthyl End-Capped Oligothiophenes as Organic Semiconductors: Effect of Chain Length and End-Capping Groups. Adv. Funct. Mater. 2007, 17, 19401951.

(20) Huss-Hansen, M. K.; Lauritzen, A. E.; Bikondoa, O.; Torkkeli, M.; Tavares, L.; Knaapila, 
M.; Kjelstrup-Hansen, J. Structural Stability of Naphthyl End-Capped Oligothiophenes in Organic Field-Effect Transistors Measured by Grazing-Incidence X-Ray Diffraction in Operando. Org. Electron. 2017, 49, 375-381.

(21) Balzer, F.; Schiek, M.; Osadnik, A.; Wallmann, I.; Parisi, J.; Rubahn, H. G.; Lützen, A. Substrate Steered Crystallization of Naphthyl End-Capped Oligothiophenes into Nanofibers: The Influence of Methoxy-Functionalization. Phys. Chem. Chem. Phys. 2014, $16,5747-5754$.

(22) Geim, A. K.; Novoselov, K. S. The Rise of Graphene. Nat. Mater. 2007, 6, 183-191.

(23) Zhu, Y.; Murali, S.; Cai, W.; Li, X.; Suk, J. W.; Potts, J. R.; Ruoff, R. S. Graphene and Graphene Oxide: Synthesis, Properties, and Applications. Adv. Mater. 2010, 22, 39063924.

(24) Lin, L.; Deng, B.; Sun, J.; Peng, H.; Liu, Z. Bridging the Gap between Reality and Ideal in Chemical Vapor Deposition Growth of Graphene. Chem. Rev. 2018, 118, 9281-9343.

(25) Pang, S.; Hernandez, Y.; Feng, X.; Müllen, K. Graphene as Transparent Electrode Material for Organic Electronics. Adv. Mater. 2011, 23, 2779-2795.

(26) Park, J.; Lee, W. H.; Huh, S.; Sim, S. H.; Kim, S. Bin; Cho, K.; Hong, B. H.; Kim, K. S. Work-Function Engineering of Graphene Electrodes by Self-Assembled Monolayers for High-Performance Organic Field-Effect Transistors. J. Phys. Chem. Lett. 2011, 2, 841845.

(27) Lee, W. H.; Park, J.; Sim, S. H.; Lim, S.; Kim, K. S.; Hong, B. H.; Cho, K. SurfaceDirected Molecular Assembly of Pentacene on Monolayer Graphene for High- 
Performance Organic Transistors. J. Am. Chem. Soc. 2011, 133, 4447-4454.

(28) Park, B.; Kim, K.; Park, J.; Lim, H.; Lanh, P. T.; Jang, A.-R.; Hyun, C.; Myung, C. W.; Park, S.; Kim, J. W.; et al. Anomalous Ambipolar Transport of Organic Semiconducting Crystals via Control of Molecular Packing Structures. ACS Appl. Mater. Interfaces 2017, 9, 27839-27846.

(29) Nguyen, N. N.; Jo, S. B.; Lee, S. K.; Sin, D. H.; Kang, B.; Kim, H. H.; Lee, H.; Cho, K. Atomically Thin Epitaxial Template for Organic Crystal Growth Using Graphene with Controlled Surface Wettability. Nano Lett. 2015, 15, 2474-2484.

(30) Nguyen, N. N.; Lee, H. C.; Kang, B.; Jo, M.; Cho, K. Electric-Field-Tunable Growth of Organic Semiconductor Crystals on Graphene. Nano Lett. 2019, 19, 1758-1766.

(31) Hlawacek, G.; Khokhar, F. S.; Van Gastel, R.; Poelsema, B.; Teichert, C. Smooth Growth of Organic Semiconductor Films on Graphene for High-Efficiency Electronics. Nano Lett. 2011, 11, 333-337.

(32) Chen, W.; Huang, H.; Thye, A.; Wee, S. Molecular Orientation Transition of Organic Thin Films on Graphite: The Effect of Intermolecular Electrostatic and Interfacial Dispersion Forces. Chem. Commun. 2008, No. 36, 4276-4278.

(33) Balzer, F.; Henrichsen, H. H.; Klarskov, M. B.; Booth, T. J.; Sun, R.; Parisi, J.; Schiek, M.; Bøggild, P. Directed Self-Assembled Crystalline Oligomer Domains on Graphene and Graphite. Nanotechnology 2014, 25, 035602.

Ha, T. J.; Akinwande, D.; Dodabalapur, A. Hybrid Graphene/Organic Semiconductor Field-Effect Transistors. Appl. Phys. Lett. 2012, 101, 99-102. 
(35) Chhikara, M.; Pavlica, E.; Matković, A.; Beltaos, A.; Gajić, R.; Bratina, G. Pentacene on Graphene: Differences between Single Layer and Bilayer. Carbon N. Y. 2014, 69, 162168.

(36) Zhou, L.; Fox, L.; Włodek, M.; Islas, L.; Slastanova, A.; Robles, E.; Bikondoa, O.; Harniman, R.; Fox, N.; Cattelan, M.; et al. Surface Structure of Few Layer Graphene. Carbon N. Y. 2018, 136, 255-261.

(37) Yoshikawa, G.; Sadowski, J. T.; Al-Mahboob, A.; Fujikawa, Y.; Sakurai, T.; Tsuruma, Y.; Ikeda, S.; Saiki, K. Spontaneous Aggregation of Pentacene Molecules and Its Influence on Field Effect Mobility. Appl. Phys. Lett. 2007, 90, 251906.

(38) Heinemeyer, U.; Broch, K.; Hinderhofer, A.; Kytka, M.; Scholz, R.; Gerlach, A.; Schreiber, F. Real-Time Changes in the Optical Spectrum of Organic Semiconducting Films and Their Thickness Regimes during Growth. Phys. Rev. Lett. 2010, 104, 257401.

(39) Mannsfeld, S. C. B.; Tang, M. L.; Bao, Z. Thin Film Structure of TriisopropylsilylethynylFunctionalized Pentacene and Tetraceno[2,3-b]Thiophene from Grazing Incidence x-Ray Diffraction. Adv. Mater. 2011, 23, 127-131.

(40) Thomas, E. M.; Brady, M. A.; Nakayama, H.; Popere, B. C.; Segalman, R. A.; Chabinyc, M. L. X-Ray Scattering Reveals Ion-Induced Microstructural Changes During Electrochemical Gating of Poly(3-Hexylthiophene). Adv. Funct. Mater. 2018, 28, 1803687.

(41) Saito, M.; Koganezawa, T.; Osaka, I. Understanding Comparable Charge Transport Between Edge-on and Face-on Polymers in a Thiazolothiazole Polymer System. ACS 
Appl. Polym. Mater. 2019, 1, 1257-1262.

(42) Huang, Y.-F.; Wang, C.-K.; Lai, B.-H.; Chung, C.-L.; Chen, C.-Y.; Ciou, G.-T.; Wong, K.-T.; Wang, C.-L. Influences of Structural Modification of S , N -Hexacenes on the Morphology and OFET Characteristics. ACS Appl. Mater. Interfaces 2019, 11, 2175621765.

(43) Kowarik, S.; Gerlach, A.; Sellner, S.; Schreiber, F.; Cavalcanti, L.; Konovalov, O. RealTime Observation of Structural and Orientational Transitions during Growth of Organic Thin Films. Phys. Rev. Lett. 2006, 96, 125504.

(44) Kowarik, S.; Gerlach, A.; Schreiber, F. Organic Molecular Beam Deposition: Fundamentals, Growth Dynamics, and in Situ Studies. J. Phys. Condens. Matter 2008, 20, 184005.

(45) Kowarik, S.; Gerlach, A.; Skoda, M. W. A.; Sellner, S.; Schreiber, F. Real-Time Studies of Thin Film Growth: Measurement and Analysis of X-Ray Growth Oscillations beyond the Anti-Bragg Point. Eur. Phys. J. Spec. Top. 2009, 167, 11-18.

(46) Richter, L. J.; Delongchamp, D. M.; Amassian, A. Morphology Development in SolutionProcessed Functional Organic Blend Films: An in Situ Viewpoint. Chem. Rev. 2017, 117, $6332-6366$.

(47) Hodas, M.; Siffalovic, P.; Nádaždy, P.; Mrkyvková, N.; Bodík, M.; Halahovets, Y.; Duva, G.; Reisz, B.; Konovalov, O.; Ohm, W.; et al. Real-Time Monitoring of Growth and Orientational Alignment of Pentacene on Epitaxial Graphene for Organic Electronics. ACS Appl. Nano Mater. 2018, 1, 2819-2826. 
(48) Liscio, F.; Albonetti, C.; Broch, K.; Shehu, A.; Quiroga, S. D.; Ferlauto, L.; Frank, C.; Kowarik, S.; Nervo, R.; Gerlach, A.; et al. Molecular Reorganization in Organic FieldEffect Transistors and Its Effect on Two-Dimensional Charge Transport Pathways. ACS Nano 2013, 7, 1257-1264.

(49) Bommel, S.; Kleppmann, N.; Weber, C.; Spranger, H.; Schäfer, P.; Novak, J.; Roth, S. V.; Schreiber, F.; Klapp, S. H. L.; Kowarik, S. Unravelling the Multilayer Growth of the Fullerene C60 in Real Time. Nat. Commun. 2014, 5, 5388.

(50) Hong, S.; Amassian, A.; Woll, A. R.; Bhargava, S.; Ferguson, J. D.; Malliaras, G. G.; Brock, J. D.; Engstrom, J. R. Real Time Monitoring of Pentacene Growth on SiO2 from a Supersonic Source. Appl. Phys. Lett. 2008, 92, 253304.

(51) Wang, Y.; Zheng, Y.; Xu, X.; Dubuisson, E.; Bao, Q.; Lu, J.; Loh, K. P. Electrochemical Delamination of CVD-Grown Graphene Film: Toward the Recyclable Use of Copper Catalyst. ACS Nano 2011, 5, 9927-9933.

(52) Graphenea S.A. Home Page https://www.graphenea.com/ (accessed Dec 18, 2019).

(53) Ritley, K. A.; Krause, B.; Schreiber, F.; Dosch, H. A Portable Ultrahigh Vacuum Organic Molecular Beam Deposition System for in Situ X-Ray Diffraction Measurements. Rev. Sci. Instrum. 2001, 72, 1453-1457.

(54) Jiang, Z. GIXSGUI: A MATLAB Toolbox for Grazing-Incidence X-Ray Scattering Data Visualization and Reduction, and Indexing of Buried Three-Dimensional Periodic Nanostructured Films. J. Appl. Crystallogr. 2015, 48, 917-926.

(55) Als-Nielsen, J.; McMorrow, D. Elements of Modern X-Ray Physics, 2nd ed.; John Wiley 
\& Sons, Inc.: Hoboken, NJ, 2011; pp 25-27.

(56) Choi, W.; Shehzad, M. A.; Park, S.; Seo, Y. Influence of Removing PMMA Residues on Surface of CVD Graphene Using a Contact-Mode Atomic Force Microscope. RSC Adv. 2017, 7, 6943-6949.

(57) Ribierre, J.; Tanaka, T.; Zhao, L.; Yokota, Y.; Matsumoto, S.; Hashizume, D.; Takaishi, K.; Muto, T.; Heinrich, B.; Méry, S.; et al. Simultaneous Edge-on to Face-on Reorientation and 1D Alignment of Small П-Conjugated Molecules Using Room-Temperature Mechanical Rubbing. Adv. Funct. Mater. 2018, 28, 1707038.

(58) Lee, H.; Kim, J. H.; Dhakal, K. P.; Lee, J. W.; Jung, J. S.; Joo, J.; Kim, J. Anisotropic Optical Absorption of Organic Rubrene Single Nanoplates and Thin Films Studied by $\mu$ Mapping Absorption Spectroscopy. Appl. Phys. Lett. 2012, 101, 113103.

(59) Lauritzen, A. E.; Torkkeli, M.; Bikondoa, O.; Linnet, J.; Tavares, L.; Kjelstrup-Hansen, J.; Knaapila, M. Structural Evaluation of 5,5'-Bis(Naphth-2-Y1)-2,2'-Bithiophene in Organic Field-Effect Transistors with n -Octadecyltrichlorosilane Coated SiO 2 Gate Dielectric. Langmuir 2018, 34, 6727-6736.

(60) Surin, M.; Hennebicq, E.; Ego, C.; Marsitzky, D.; Grimsdale, A. C.; Müllen, K.; Brédas, J. L.; Lazzaroni, R.; Leclère, P. Correlation between the Microscopic Morphology and the Solid-State Photoluminescence Properties in Fluorene-Based Polymers and Copolymers. Chem. Mater. 2004, 16, 994-1001.

(61) Mannsfeld, S. C. B.; Briseno, A. L.; Liu, S.; Reese, C.; Roberts, M. E.; Bao, Z. Selective Nucleation of Organic Single Crystals from Vapor Phase on Nanoscopically Rough 
Surfaces. Adv. Funct. Mater. 2007, 17, 3545-3553.

(62) Wrana, D.; Kratzer, M.; Szajna, K.; Nikiel, M.; Jany, B. R.; Korzekwa, M.; Teichert, C.; Krok, F. Growth of Para-Hexaphenyl Thin Films on Flat, Atomically Clean versus AirPassivated TiO2(110) Surfaces. J. Phys. Chem. C 2015, 119, 17004-17015.

(63) Knaapila, M.; Lyons, B. P.; Hase, T. P. A.; Pearson, C.; Petty, M. C.; Bouchenoire, L.; Thompson, P.; Serimaa, R.; Torkkeli, M.; Monkman, A. P. Influence of Molecular Weight on the Surface Morphology of Aligned, Branched Side-Chain Polyfluorene. Adv. Funct. Mater. 2005, 15, 1517-1522.

(64) Chi, C.; Lieser, G.; Enkelmann, V.; Wegner, G. Packing and Uniaxial Alignment of Liquid Crystalline Oligofluorenes. Macromol. Chem. Phys. 2005, 206, 1597-1609. 
TOC

"Surface-Controlled Crystal Alignment of Naphthyl End-Capped Oligothiophene on Graphene:

Thin-Film Growth Studied by In Situ X-ray Diffraction"

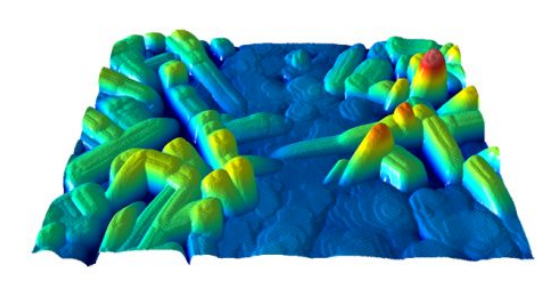

by Mathias K. Huss-Hansen, Martin Hodas, Nada Mrkyvkova, Jakub Hagara, Bjarke B. E.

Jensen, Andreas Osadnik, Arne Lützen, Eva Majková, Peter Siffalovic, Frank Schreiber, Luciana

Tavares, Jakob Kjelstrup-Hansen, and Matti Knaapila. 
1

2

3

4

5

6

7

8

9

10

11

12

13

14

15

16

17

18

19

20

21

22

23

24

25

26

27

28

29

30

31

32

33

34

35

36

37

38

39

40

41

42

43

44

45

46

47

48

49

50

51

52

53

54

55

56

57

58

59

60
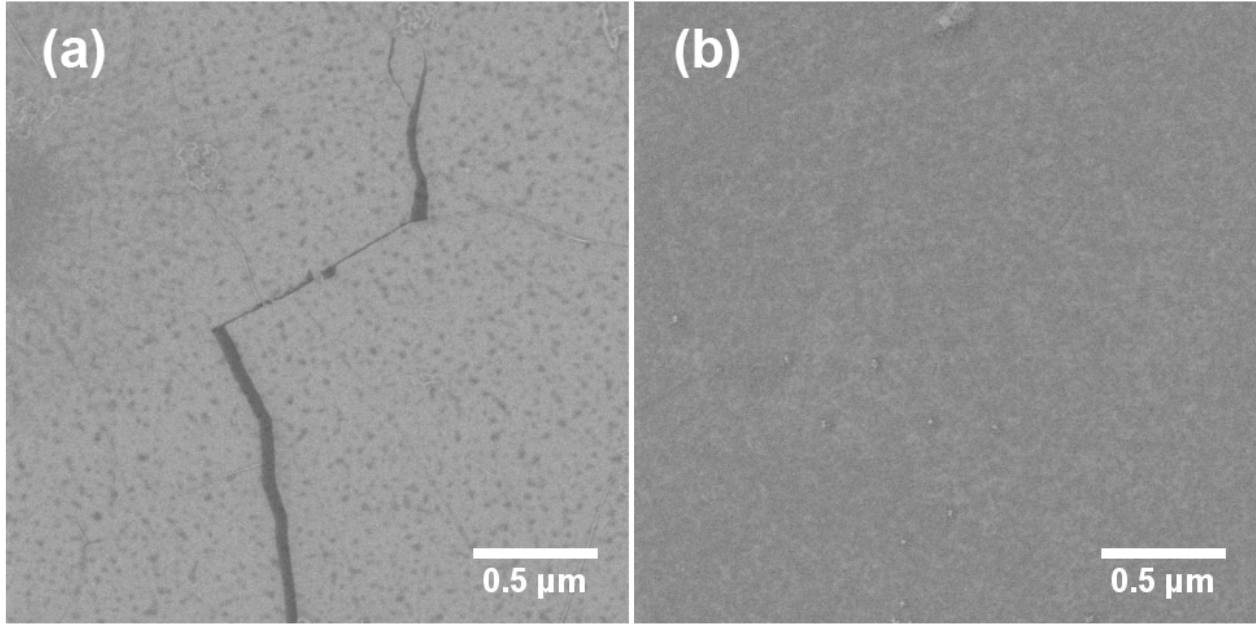

Figure 1. HIM images of the graphene surfaces. (a) Type I graphene. (b) Type II graphene. 


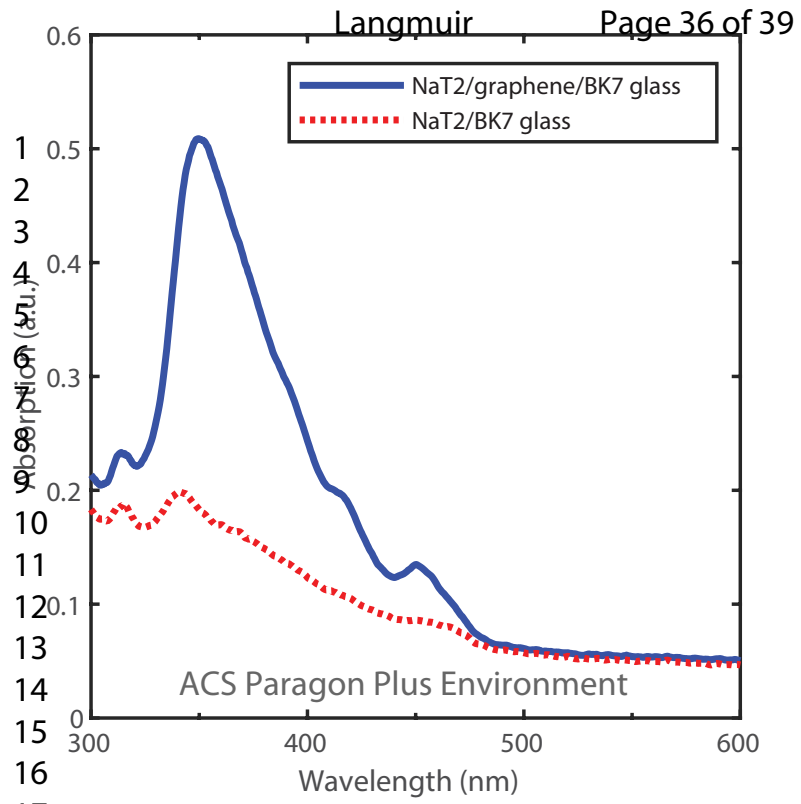


(a)

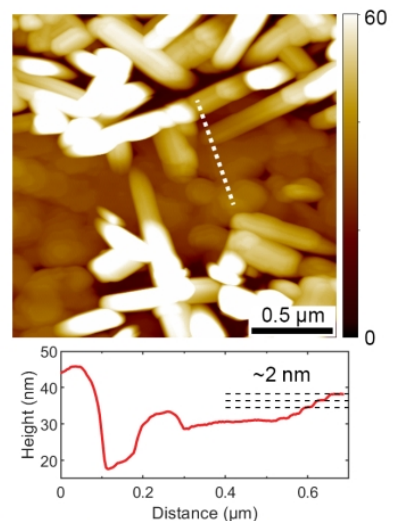

(c)

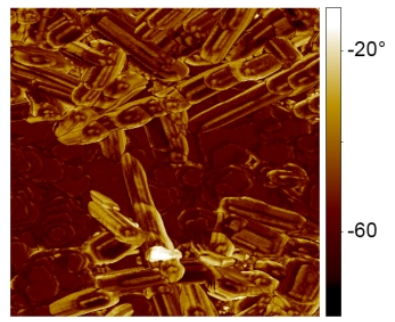

(b)
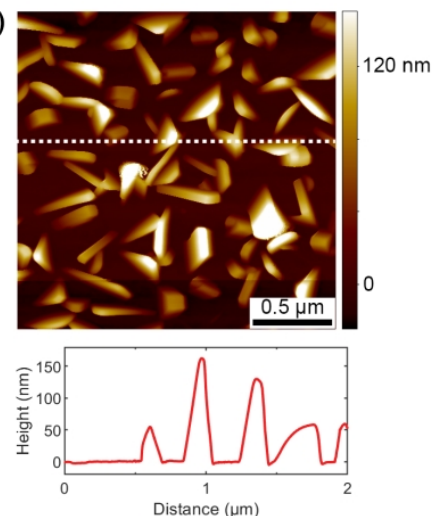

(d)

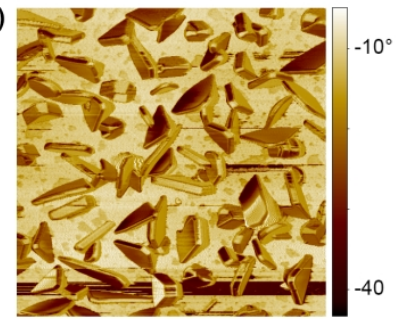

Figure 3. AFM images of the final NaT2 thin films grown on CVD graphene films. (a,b) AFM topographies of the films deposited on Type I and Type II graphene, respectively, with corresponding characteristic crosssectional height profiles. (c,d). AFM phase images corresponding to the topographies above. 


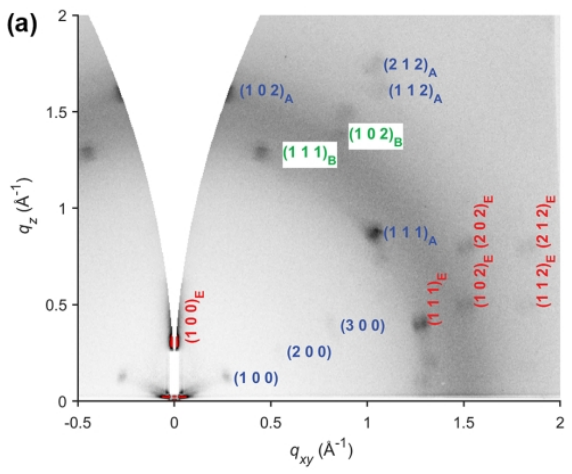

(b)

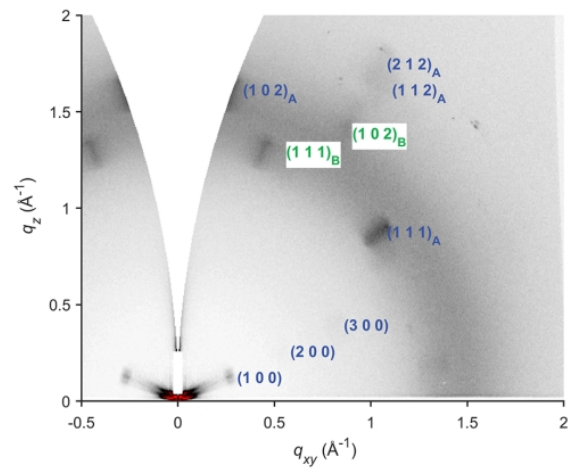

(c)
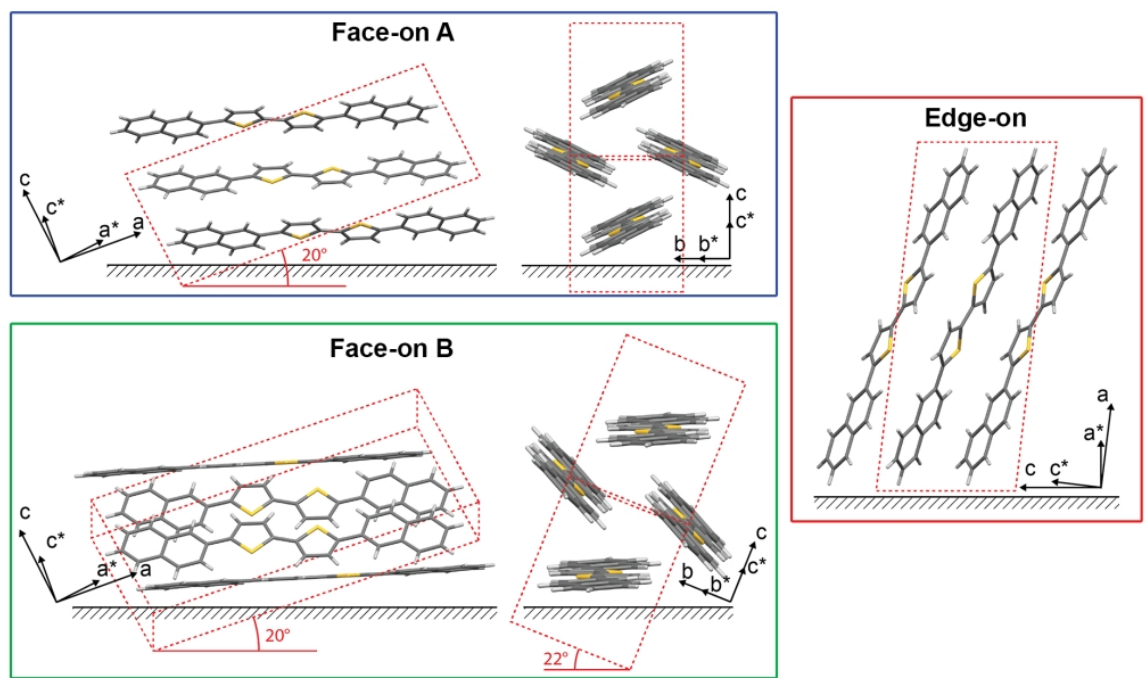

Figure 4. (a,b) GIXRD patterns of NaT2 thin films deposited on Type I and Type II graphene substrates, respectively. (c) Proposed arrangements of NaT2 molecules with face-on and edge-on orientations. For all schematics, the view is taken to be parallel to the substrate plane. The right view in the two face-on schematics is rotated by 90 degrees to illustrate the difference in the tilt of the b-axis (corresponding to a view along the molecular backbone). The direct- and reciprocal lattice vectors are shown in the bottom corner and the unit cell is marked by the dotted lines. The border colors correspond to the color of the reflection indices in (a) and (b). 
Page 39 of 39

Langmuir

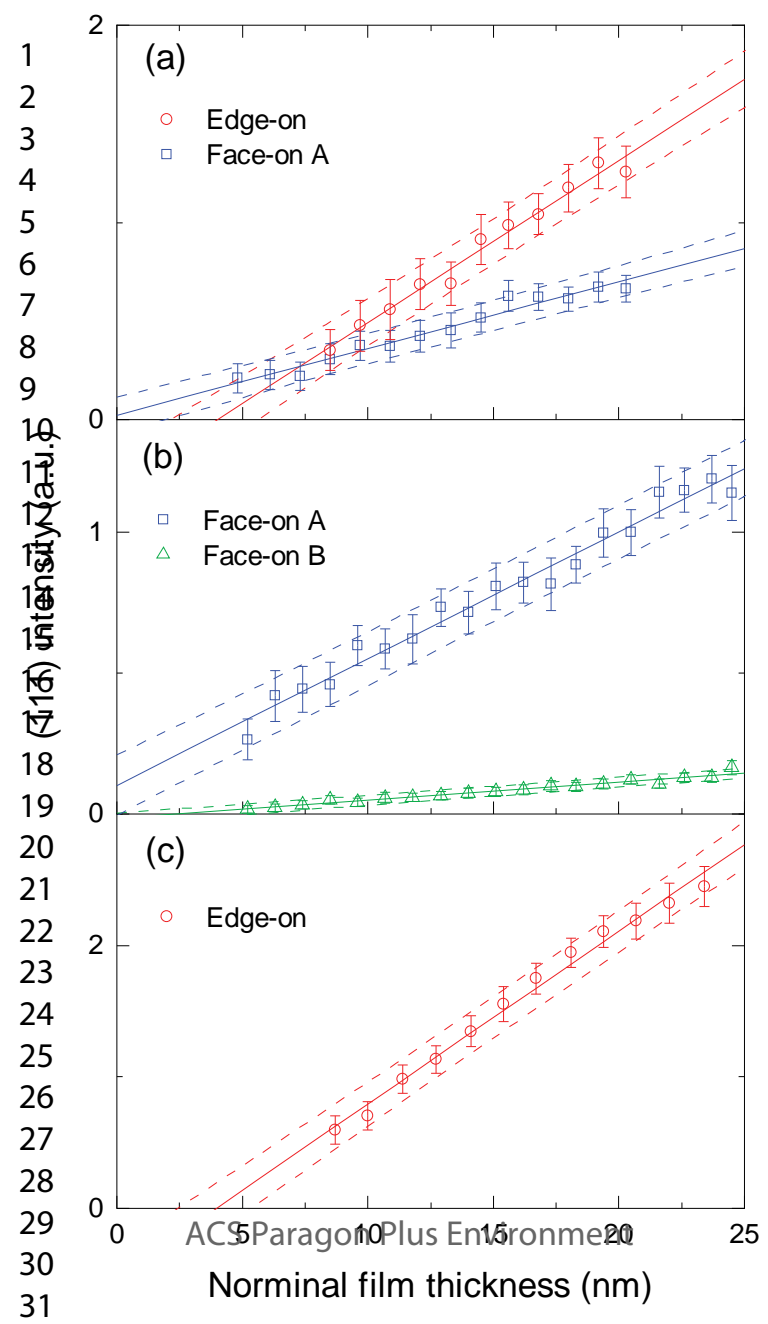

